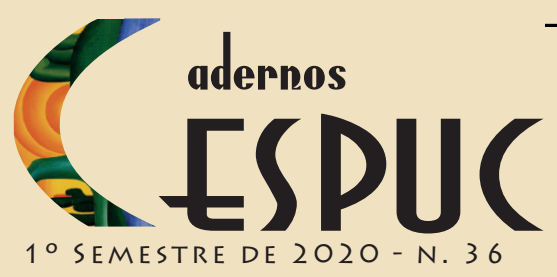

\title{
A CONSTRUÇÃO DO JOGO METAFÓRICO EM L'ÉLÉCANCE DU HÉRISSON: PROCESSOS ESTÉTICOS DE COLONIZAÇÃO E HIERARQUIZAÇÃO SIMBÓLICA ${ }^{1}$
}

\author{
Jozelma de Oliveira Ramos*
}

\begin{abstract}
Resumo
Sabe-se que numa construção estético-literária, a partir do jogo metafórico realizado no e pelo discurso, uma realidade é elaborada de maneira extremamente particular. Por conseguinte, cria-se por meio da arte e da literatura um novo olhar sobre a vida, a sociedade e, claro, sobre os seres humanos e suas complexas relações interpessoais de poder. Dentro dessa perspectiva é que serão discutidos, no presente artigo, alguns processos metafóricos arquitetados pela autora francesa Muriel Barbery em L'élégance du hérisson (2006). Parte-se do princípio de que tal proposta estética é utilizada pela autora para marcar a alternância entre as vozes narrativas, o que desencadeia, entre outras coisas, o (des)velamento das relações de poder aí encenadas, a que denominamos relações hierárquicas subjetivas de "colonização simbólica" que se impõem entre as personagens da trama em questão.
\end{abstract}

Palavras-chave: Metáfora. Jogo enunciativo. Relações de poder. Colonização simbólica. Arte.

\section{LA CONSTRUCTION DU JEU MÉTAPHORIQUE DANS L'ÉLÉCANCE DU HÉRISSON: PROCESSUS ESTHÉTIQUES DE COLONISATION ET HIÉRARCHIE SYMBOLIQUE}

Résumé

Tout d'abord, le jeu métaphorique de la construction esthétique-littéraire, réalisé par le discours, peut exprimer une certaine réalité humaine d'une façon très particulière. Par conséquent l'art et la littérature engendrent un nouveau regard sur la vie, la société et, bien évidemment, sur les êtres humains dans leurs relations interpersonnelles de pouvoir. Dans ce sens, il sera discuté dans cet article le processus métaphorique construit par Barbery dans L'élégance du Hérisson (2006). Tel processus est aussi utilisé par l'auteur pour souligner l'alternance entre les voix narratives ; cela déclenche, parmi d'autres choses, le jeu métaphorique et ses effets de sens dans le récit ici étudié. Enfin, il est possible de dire que l'un de ces effets de sens est le dévoilement des relations hiérarchiques subjectives de « colonisation symbolique » entre les personnages de L'élégance du hérisson.

Mots-clés : Métaphore. Jeu énonciatif. Relations de pouvoir. Colonisation symbolique. L’art.

Recebido em 21/05/ 2020

Aceito em 20/07/2020

1 Este trabalho é parte da tese de doutoramento intitulada "Os processos enunciativos e as relações interpessoais de (des)colonização simbólica em A árvore das Palavras e L'élégance du hérisson."

*Pontifícia Universidade Católica de Minas Gerais (PUC - Minas). Doutora em Literaturas de Língua Portuguesa.

ORCiD: http://orcid.org/0000-0002-4834-2347. 
[...] des hommes et des femmes liés par la conscience partagée de leur fragilité d'être nus et d'une collusion de désir qui les associait dans le vertige de l'art...

(BARBERY, 2015, p.128-129)

A narrativa de L'élégance du Hérisson (2006) foi elaborada por Muriel Barbery, por meio da alternância entre as vozes das personagens narradoras Renée e Paloma. A história se passa em um prédio de classe alta, em Paris, em que a primeira trabalha como concierge, "veuve, petite, laide et grassouillette $[\ldots]^{1}$ " (BARBERY, 2006, p.15), como ela mesma se descreve. Já a segunda, uma menina de 12 anos, que assim se apresenta: " [...] je suis très intelligente. Exceptionnellement intelligente [...] je tente, au collège, de réduire mes performances, mais même avec ça, je suis toujours la première. " ${ }^{2}$ (BARBERY, 2006, p.20 - 21). No entanto, não obstante a forma diferente como as narradoras se descrevem e se apresentam, ao longo da narrativa, descobre-se que ambas partilham de um profundo interesse pelas artes e pela literatura e convergem, também de forma especular, no que diz respeito à rejeição dos arranjos sociais que envolvem a comunidade na qual estão inseridas.

Nessa perspectiva, pode-se dizer que em L'élégance du Hérisson (2006), a alternância das vozes narrativas nas situações de enunciação entre seus interlocutores desencadeia o jogo metafórico elaborado pela referida autora e revela, por conseguinte, o processo hierárquico das relações interpessoais de "colonização simbólica". Para melhor se entender tal afirmação, é preciso apontar para a construção narrativa, marcada pelas duas diferentes narradoras: Renée, a concièrge de um prédio habitado por famílias ricas, e Paloma, uma das filhas de uma dessas famílias. A cada uma delas são atribuídos, em alternância, os capítulos da obra, em que se inserem cenas enunciativas, em desdobramento.

Vejam-se, por exemplo, as primeiras metáforas que aparecem na referida obra a partir da relação entre as personagens Renée e Pallières, outro jovem do mesmo prédio, na ocasião em que a concièrge é surpreendida ao referir-se a textos lidos por ela:

— Qui sème le désir récolte l'oppression, suis-je tout près de murmurer comme si seul mon chat m'écoutait. Mais Antoine Pallières, dont la répugnante et embryonnaire moustache n'emporte avec elle rien de félin, me regarde, incertain de mes paroles étranges. Comme toujours, je suis sauvée par l'incapacité qu'ont les êtres à croire à ce qui fait exploser les cadres de leurs petites habitudes mentales. Une concierge ne lit pas l'Idéologie allemande et serait conséquemment bien incapable de citer la onzième thèse sur Feuerbach. De surcroît, une concierge qui lit Marx lorgne forcément vers la subversion, vendue à un diable qui s'appelle CGT. Qu'elle puisse le lire pour l'élévation de l'esprit est une incongruité qu'aucun bourgeois ne forme. (BARBERY, 2006, p.13-14 - grifo nosso) ${ }^{3}$

1 Viúva, baixinha, feia e gordinha (BARBERY, 2008, p.15)

2 Eu sou muito inteligente. Excepcionalmente inteligente, até [...] tento, no colégio, reduzir meu desempenho, mas mesmo assim, sou sempre a primeira da classe. (BARBERY, 2008, p.21)

3 - "Quem semeia desejo colhe opressão", estou prestes a murmurar como se só meu gato me escutasse. Mas Antoine Pallières, cujo bigode embrionário e repugnante não tem nada de felino, olha para mim, duvidando de minhas estranhas palavras. Como sempre, sou salva pela incapacidade dos seres humanos de acreditar naquilo que explode as molduras de seus pequenos hábitos mentais. Uma zeladora não lê a Ideologia alemã, e, por conseguinte, seria incapaz de citar a décima primeira tese sobre Feuerbach. Além disso, uma zeladora que lê Marx está, necessariamente, de olho na subversão, e se vendeu a um diabo que se chama Confederação Geral dos Trabalhadores, a CGT. Que consiga lê-lo para a elevação do espírito é uma incongruência que burguês nenhum admite. 
A cena enunciativa acima faz parte do capítulo que dá início à trama, intitulado de "Marx (préambule)". Essa referência metonímica, presente no título, demarca, como se sabe, a resistência às relações de poder institucionalizadas e perpetuadas ao longo dos séculos. No entanto, a alternância entre os interlocutores, no desenrolar desse capítulo, e seus discursos aí representados, também denota, por meio do jogo metafórico ali estabelecido, como as liberdades individuais estão conformadas pelas mais diversas formas sociais interiorizadas de colonização simbólica, como apontadas, no excerto e em outras cenas, pela relação dicotômica burguês-proletário.

Tal processo delineia, exatamente, o lugar político-social ao qual está "abandonada" 4 a personagem em questão, qual seja, Renée, a concierge. Tendo em vista, por exemplo, o destaque, no jogo metafórico arquitetado por Barbery nesse capítulo, dos estereótipos inerentes a uma espécie de voz coletiva "ignorante" com respeito à imagem limitada que se faz do outro: "Comme toujours, je suis sauvée par l'incapacité qu'ont les êtres à croire à ce qui fait exploser les cadres de leurs petites habitudes mentales ” (BARBERY, 2006, p.13).

Assim, o jogo enunciativo estabelecido durante a relação "eu - tu", para além de fazer emergir o estereótipo da mediocridade mental humana, por meio do movimento subjetivo de abstração das palavras ou expressões, utilizadas fora do seu sentido ordinário (KONRAD, apud JAMAIT, 2008), denota, sobretudo, o processo de hierarquização, sob o qual se conformam as relações de poder, principalmente, na modernidade. Consideramos com FOUCAULT (1976) que, a partir dos séculos XVIII e XIX, tais relações de poder se modificaram profundamente, com a criação de instituições que introjetam nos indivíduos modernos, segregações e hierarquizações sociais ${ }^{5}$ muito bem demarcadas. A continuação da cena traz à tona o relato autobiográfico de Renée, a concierge, contrapondo-a à vida dos moradores do prédio:

Je m'appelle Renée. J'ai cinquante-quatre ans. Depuis vingt-sept ans, je suis la concierge du 7 rue de Grenelle, un bel hôtel particulier avec cour et jardin intérieurs, scindé en huit appartements de grand luxe, tous habités, tous gigantesques. Je suis veuve, petite, laide, grassouillette, j'ai des oignons aux pieds et, à en croire certains matins auto-incommodants, une haleine de mammouth. [...] je corresponds si bien à ce que la croyance sociale a aggloméré en paradigme de la concierge d'immeuble que je suis un des multiples rouages qui font tourner la grande illusion universelle selon laquelle la vie a un sens qui peut être aisément déchiffré. (BARBERY, 2006, p.15 - grifo nosso) ${ }^{6}$

\section{(BARBERY, 2008, p.14 - grifo nosso)}

4 A palavra "abandono" está sendo utilizada aqui no sentido desenvolvido por Giorgio Agamben (2016) que, ao estudar o "paradoxe de souverainité", discorre como a relação original entre a lei e a vida, não é de implicação, mas de abandono. Nesse sentido, para Agamben, o indivíduo, na modernidade, é colocado em "poder de" está, pois, sujeito a toda forma de opressão e exclusão: [...] à l'origine, dans les langues romaines, mettre à bandon, à ban donner signifie aussi bien "mettre au pouvoir de" que "laisser en liberte" (AGAMBEN, 2016, p.34)

5 [...\}les rudiments d'anatomo -et de biopolitique, inventés au XIII siècles, comme techniques de pouvoir présentes à tous les niveaux du corps social et utilisées par des institutions très diverses (la famille comme l'armée, l'école ou la police, la médicine individuelle ou l'administration des collectivités), ont agi au niveau des processus économiques, de leur déroulement, des forces qui y sont à l'œuvre et les soutiennent; ils sont opéré aussi comme facteurs de ségrégation et de hiérarchisation sociale [...] (FOCAULT, 1976, p.14).

6 Meu nome é Renée. Tenho cinquenta e quatro anos. Há vinte e sete sou a concierge, a zeladora do número 7 da Rue de Grenelle, um belo palacete com pátio e jardim internos, dividido em oito apartamentos de alto luxo, todos habitados, todos gigantescos. Sou viúva, baixinha, feia, gordinha, tenho calos nos pés e, em certas manhãs autoincômodas, um hálito de mamute. [...] correspondo tão bem ao que a crença social associou ao paradigma da 
Na cena enunciativa acima citada, a frase: « je suis un des multiples rouages qui font tourner la grande illusion universelle selon laquelle la vie a un sens qui peut être aisément déchiffré ", exemplifica, dentro do referido jogo metafórico proposto pela autora, a homogeneização opressora - "je suis un des multiples rouages" - inerente à maquinaria que leva ao processo de hierarquização e colonização simbólica, que marca os lugares sociais.

Ainda nessa cena, percebe-se, para além de uma relação "eu-eu/tu", na qual a personagem faz um relato autobiográfico descritivo de si mesma e de sua profissão de concierge, também uma voz coletiva por meio da interlocução dialógica aí estabelecida. Tal relação é colocada em evidência após a inserção de uma metáfora que sugere a auto depreciação da personagem, mas que está, ao mesmo tempo, carregada de uma multiplicidade de vozes que projetam, mais uma vez, relações de poder hierarquizadas: "[j'ai] une haleine de mammouth" (BARBERY, 2006, p.15). Por outro lado, pode-se afirmar também que existe aqui uma metáfora para a tentativa de resistência de embate social, pois, "o hálito de mamute" aponta para algo selvagem, que pode não se deixar domar.

Como se vê as metáforas acima indicam, além do que já foi mencionado, uma "auto animalização" - "mammouth" - assim como uma "auto coisificação" - "rouages" - repercutida de uma voz coletiva "soberana" e excludente, que faz com que o indivíduo simbolicamente "colonizado" confirme e reverbere sua posição de "inferioridade" ao mesmo tempo em que tenta resistir, inutilmente, a essa hierarquização. Por conseguinte, tais metáforas mostram esse indivíduo como parte do sistema social, sob a forma de suas engrenagens - "rouages" - , e evidenciam sua permanência numa posição de exclusão social, o que é fruto do sistema moderno que distingue "inclusão" e "pertencimento"(AGAMBEN,2016) ${ }^{7}$ e provoca uma espécie de "homogeneização" ideológica manipuladora, fruto de uma colonização simbólica tão arraigada, que se torna imperceptível para os sujeitos imersos nesse sistema.

Ainda dentro dessa perspectiva dialógico-enunciativa reforçada pelo jogo metafórico proposto por Barbery, como processo desencadeador das relações interpessoais de colonização, vejamos duas cenas nas quais a personagem Paloma ganha relevo:

Ma mère... Eh bien ma mère n'est pas exactement une lumière mais elle est éduquée. Elle a un doctorat de lettres. Elle écrit ses invitations à dîner sans fautes et passe son temps à nous assommer avec des références littéraires ("Colombe, ne fais pas ta Guermantes ", "Ma puce, tu es une vraie Sanseverina "). (BARBERY, 2006, p.20 - grifo nosso) ${ }^{8}$

[...] ça y est, j'ai été capable de repérer dans le monde des mouvements immobiles ; est-ce que ça, ça vaut la peine de continuer ? À ce moment-là, un joueur français a perdu son short dans un maul et, tout d'un coup, je me suis sentie complètement déprimée parce que ça a fait rire tout le monde aux larmes, y compris papa qui s'en est retapé une petite bière,

concierge, que sou uma das múltiplas engrenagens que fazem girar a grande ilusão universal de que a vida tem um sentido que pode ser facilmente decifrado. (BARBERY, 2008, p.15 - grifo nosso)

7 «[...] L'exception exprime précisément l'impossibilité pour un système de faire coïncider l'inclusion avec l'appartenance et de réduire à l'unité toutes ses parties. " (AGAMBEN, 2016, p.31)

8 Minha mãe... Bem, minha mãe não é propriamente uma águia, mas é educada. Tem doutorado em letras. Escreve sem erros seus convites para jantar e passa o tempo a nos infernizar com referências literárias ("Colombe, não

banque a Guermantes", "Minha flor, você é uma verdadeira Sanseverina" - grifo nosso). (BARBERY, 2008, p.20) 
malgré deux siècles de protestantisme familial. Moi, j'avais l'impression d'une profanation. (BARBERY, 2006, p.39 - grifo nosso) ${ }^{9}$

Nas duas cenas enunciativas acima a personagem Paloma descreve para o seu interlocutor, em primeira e terceira pessoa, características de seus pais. A primeira cena faz parte do capítulo intitulado "Pensée profonde $n^{\circ} 1 " 10$ no qual a personagem arquiteta o seu suicídio para o dia do seu aniversário de treze anos. Já o segundo, está no capítulo "Journal du mouvement du monde $n^{\circ} 1$ " 11 , no qual a personagem tenta buscar na arte e no movimento dos corpos e das coisas uma razão para não dar cabo à vida.

Assim, na primeira citação, as metáforas são construídas, na cena enunciativa, por meio de um olhar "triplo": o da personagem Paloma sobre si mesma, o da mãe sobre suas filhas e, por fim, o de Paloma sobre sua mãe. Com efeito, essa multiplicação de vozes e visões se torna possível porque o jogo enunciativo produz metáforas que "jogam" por meio de citações literárias: ${ }^{12}$ "Guermantes" e "Sanseverina", além da ironia presente na metáfora que caracteriza intelectualmente a personagem mãe da protagonista: " Ma mère... Eh bien ma mère n'est pas exactement une lumière " (BARBERY, 2006, p.20 - grifo nosso).

Nesse sentido, nota-se, por exemplo que a alusão à personagem proustiana "Guermantes", bem como à personagem criada por Stendhal, "Senseverina", ${ }^{13}$ denota, respectivamente, os estereótipos do burguês e do revolucionário, para metaforizar a "persona" arquitetada pela autora para as personagens Paloma e sua irmã Colombe. Além disso, evidentemente, tais metáforas proferidas pela voz da personagem Solange Josse, rica e burguesa, condensam também, ironicamente, o superficialismo intelectual da referida mãe de Paloma, construído a partir do jogo enunciativo proposto por Barbery.

Percebem-se aí, pois, ecos do superficialismo intelectual, conforme analisou Mme de Staël (1813), ao comparar a intelectualidade francesa à alemã: "[...] Na França, quase que só se lê para que se fale que se leu [...]”. ${ }^{14}$ Por certo, na narrativa de Barbery, como exemplificado no excerto acima, destaca-se esse lugar de domínio e superioridade do saber filosófico literário, ainda que raso, como verniz social exposto em detrimento do outro, contribuindo para o aprofundamento do fosso das relações interpessoais ali hierarquizadas.

Notadamente, esse saber é colocado em xeque pela narradora ao citar a formação de doutoramento da personagem Colombe como pré-requisito apenas para uma "boa escrita", como exemplificado na cena acima. Aqui, então, fica, ao mesmo tempo, demarcado e relativizado


Nesse instante, um jogador francês perdeu seu short num maul, e, de repente, me senti deprimida porque isso fez todo mundo rolar de rir, inclusive papai, que pegou mais uma cervejinha, apesar dos dois séculos de protestantismo familiar. Eu tinha a impressão de uma profanação. (BARBERY, 2008, p.41)

10 Pensamento profundo $n^{\circ} 1$

11 Jornal do movimento do mundo $n^{\circ} 1$

12 Referência à Stendhal e à Proust, respectivamente.

13 Edições eruditas de A Cartuxa de Parma transcrevem, em Apêndice, aqueles dentre os mencionados textos que certamente inspiraram a Stendhal. Há ali uma Duquesa Sanseverina, decapitada em 1612 por haver conspirado contra o Príncipe de Parma. Fonte: http://www.institutodehumanidades.com.br/index.php/c/193-a-cartuxa-de-parma-de-stendhal. Acesso em 11/04/19

14 (STAËL, Mme. de: 1813, 110 - 3, cap. I da segunda parte, apud LIMA, 2002) 


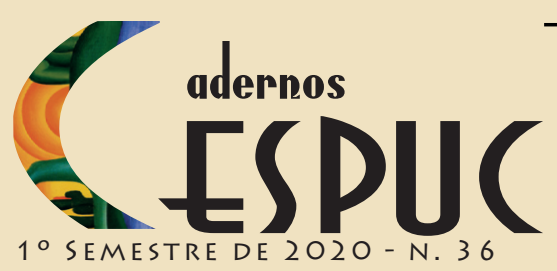

Jozeuma de Ouveira Ramos

o lugar hierárquico do intelectual burguês doutor, ao mesmo tempo em que se deprecia e se confirma o estereótipo do feminino a serviço das futilidades sociais, como outro traço de uma hierarquização e colonização social simbólica.

Na segunda cena enunciativa acima citada, por sua vez, sobrepõem-se as vozes do narrador e a voz coletiva representada pelo tradicionalismo religioso. Nessa cena, portanto, por meio da interlocução proposta, ficam marcadas não somente a figura estereotipada do "pater famílias" burguês e protestante, mas também a representatividade de um estereótipo notadamente histórico-social de dominação.

Dessa forma, essa confluência de vozes - eu/nós - produz o jogo metafórico expresso em: "papa qui s'en est retapé une petite bière, malgré deux siècles de protestantisme familial. Moi, j'avais l'impression d'une profanation"; jogo este que fica marcado pela relação entre bière protestantisme - profanation, os quais representam, graças a alternância de vozes orquestrada pela autora, o controle subjetivo da religiosidade sobre os sujeitos, como uma espécie de "pouvoir disciplinaire et normalisateur"15 (Cf. RAMBEAU, 2006). Esse controle marca não somente um conjunto de regulações sociais explícitas, mas "la technique de la direction de conscience"16 (RAMBEAU, 2006, p.73), ou seja, a dominação ou colonização simbólica não somente interpessoal, mas cultural e socialmente estabelecida.

Vejamos, então, outra cena, na qual a narradora personagem Paloma fala a respeito do personagem M. Ozu, um japonês que passa a morar no prédio. Nesse momento, mais uma vez, a mistura de vozes promove a construção do jogo metafórico e arquitetado por Barbery para a elaboração do processo estético de hierarquização e colonização simbólica:

$[\ldots]$ c'est la première fois que je rencontre quelqu'un qui cherche les gens et qui voit au-delà. Ça peut paraitre trivial mais je crois quand même que c'est profond. Nous ne voyons jamais au-delà de nos certitudes et, plus grave encore, nous avons renoncé à la rencontre, nous ne faisons que nous rencontrer nous-mêmes sans nous reconnaître dans ces miroirs permanents. Si nous nous en rendions compte, si nous prenions conscience du fait que nous ne regardons jamais que nous-même en l'autre, que nous sommes seuls dans le désert, nous deviendrions fous. Quand ma mère offre des macarons de chez Ladurée à Mme de Broglie, elle se raconte à elle-même l'histoire de sa vie et ne fait que grignoter sa propre saveur ; quand papa boit son café et lit son journal, il se contemple dans une glace tendance méthode Coué ; quand Colombe parle des conférences de Marian, elle déblatère sur son propre reflet et quand les gens passent devant la concierge, ils ne voient que le vide parce que ce n'est pas eux. Moi, je supplie le sort de m'accorder la chance de voir au-delà de moi-même et de rencontrer quelqu'un. (BARBERY, 2006, p.154) ${ }^{17}$

15 "poder disciplinar e normalizador" (RAMBEAU, 2006 - tradução nossa)

16"a técnica de direção da consciência" (RAMBEAU, 2006, p. 73 - tradução nossa)

$17[\ldots]$ é a primeira vez que encontro alguém que procura as pessoas e que vê além. Isso pode parecer trivial, mas acho, mesmo assim, que é profundo. Nunca vemos além de nossas certezas e, mais grave ainda, renunciamos ao encontro, apenas encontramos a nós mesmos sem nos reconhecer nesses espelhos permanentes. Se nos déssemos conta, se tomássemos consciência do fato de que sempre olhamos apenas para nós mesmos no outro, que estamos sozinhos no deserto, enlouqueceríamos. Quando minha mãe oferece macarons da casa Ladurée à Sra. de Broglie, conta a si mesma a história de sua vida e não faz mais que mordiscar seu próprio sabor; quando papai toma café e lê jornal, contempla-se num espelho do gênero manual de autoconvencimento; quando Colombe fala das aulas de Marian, deblatera sobre seu próprio reflexo, e; quando as pessoas passam diante da concierge, só veem o vazio porque ali não se reconhecem. De meu lado, suplico ao destino que me conceda a chance de ver algo de mim 
Nessa cena da narrativa, para além da mistura da vozes, é na relação "eu-eu”, a qual é, ao mesmo tempo, "eu-tu", que se constrói o jogo metafórico aqui proposto, o qual demarca, com efeito, as relações hierarquizadas de identificação e "desidentificação" entre as personagens citadas no excerto. Por essa razão, nessa construção enunciativa, a metáfora do espelho - "le miroir permanente" - atravessa todo o excerto e, por que não dizer, toda a narrativa de Barbery.

Para a elaboração da referida metáfora percebe-se que as vozes alternam-se entre "eu", "nós" versus tu/vós referindo a "eles" e, para cada um desses "protagonistas" das ações descritas pela narradora, a metáfora do "espelho" se desdobra numa pluralidade de "eus" que se identificam até chegar ao "vazio": "se raconte à elle-même"- "il se contemple dans une glace" - "ils ne voient que le vide". Nessa perspectiva, os seres se identificam com aquilo que lhes confere poder e status social, mas não conseguem se identificar com o outro, com o humano.

Como se vê, essa relação especular de identificação e rejeição em relação ao outro só fazse mais evidente em sociedades denominadas por Agamben (2016) de "post-démocratique du spetacle", ${ }^{18}$ ou seja, uma sociedade na qual o indivíduo e sua vida político-social se misturam a tal ponto que não há distinção entre um e outro, e a evidência social ganha corpo em detrimento da vida humana. Assim o jogo metafórico, baseado nos verbos olhar, contemplar e ver, que segue o jogo enunciativo, proposto por Barbery, culmina na valoração ou desvalorização da figura do outro e do humano.

A partir das últimas cenas citadas, até aqui, houve uma tentativa de mostrar como a alternância entre as vozes narrativas, no jogo metafórico proposto por Barbery, denota o processo hierárquico subjetivo de "colonização simbólica". Vejamos agora, a partir da cena abaixo citada - na qual Réné descreve alguns estereótipos sociais relativos às concierges como a personagem narradora constrói seu espaço social em contraponto ao dos vizinhos e seus pares, demonstrando, assim, o caráter dissimulador desse jogo metafórico nas relações de poder estabelecidas entre as personagens em L'élégance du Hérisson (2006):

[...] il est dit que les concierges regardent interminablement la télévision pendant que leurs gros chats sommeillent et que le vestibule de l'immeuble doit sentir le pot-au-feu, la soupe aux choux ou le cassoulet des familles. J'ai la chance inouïe d'être concierge dans une résidence de grand standing. Il m'était si humiliant de devoir cuisiner ces mets infâmes que l'intervention de M. de Broglie, le conseiller d'État du premier, qu'il dut qualifier auprès de sa femme de courtoise mais ferme et qui visait à chasser de l'existence commune ces relents plébéiens, fut un soulagement immense que je dissimulai du mieux que je le pus sous l'apparence d'une obéissance contrainte. (BARBERY, 2006, p.16) ${ }^{19}$

mesma e encontrar alguém. (BARBERY,2008, p.153-154)

18 Agamben (2016) desenvolve aqui a tese defendida por Foucault (1976) que trata, grosso modo, como os mecanismos de poder desenvolvidos ao longo dos séculos XVII e XVII passaram a gerir a vida humana na modernidade. No entanto, para Agamben, na sociedade contemporânea, a qual ele denomina de "pos-democracia do espetáculo”, não há uma distinção ou separação entre vida e política, ou seja, não é um controle externo, mas uma "indiferenciação" produzida pela "mistura" entre vida e política, na qual as relações de poder se aprofundam e se tornam muito mais complexas.

19 [...] está dito que as concierges assistem TV indefinidamente enquanto seus gatos gordos cochilam, e que a portaria do prédio deve cheirar a pot-au-feu, sopa de repolho ou ao cassoulet familiar. Tenho a sorte incrível de ser concierge num prédio de alto luxo. Para mim era tão humilhante ter de cozinhar esses pratos infames, que a intervenção do Senhor de Broglie - membro do Conselho de Estado, morador do primeiro andar, que ele sacramentou juntamente com a mulher, cortês, mas firme, visando expulsar da vida em comum esses maus cheiros plebeus, foi 
No trecho acima, a construção metafórica dissimuladora para delinear as relações de poder aí estabelecidas passa sobretudo pela percepção subjetiva do odor. Para Remi Digonnet (2008) em seu artigo, Les métaphores olfactives : du sensible à l'intelligible :

L'odeur est une impression, une action de presser sur, une action par laquelle une chose appliquée sur une autre y laisse une empreinte. L’odeur apparaît ainsi comme une empreinte, quelque chose qui fait trace. ${ }^{20}$ (DIGONNET, apud JAMAIT, 2008, p.19).

Nesse sentido, a cena enunciativa " exala » os odores típicos da cozinha da concierge como metáfora para a subalternidade: "le vestibule de l'immeuble doit sentir le pot-au-feu, la soupe aux choux ou le cassoulet des familles ». Pode-se dizer que esse "odor de subalternidade" é também metáfora para a presença, aparentemente, " ausente " do poder (FOUCAULT, 1976) que determina essa exclusão: "Le pouvoir est une présence absente, une virtualité pourtant dotée d'effets réels [...] qui consiste à imposer une conduite à une multiplicité restreinte d'individus. " (RAMBEAU, 2006, p.56). ${ }^{21}$

Com efeito, essa presença ausente do poder controlador de uns sobre os outros, expresso pela metáfora do odor subalterno, constitui um fator social claro de segregação e, sobretudo de controle sobre o outro (FOUCAULT, 1976), uma vez que, conforme o excerto acima citado, houve a "interdição" dos cozimentos que produziam esse odor:

[...] l'intervention de M. de Broglie, [...] et qui visait à chasser de l'existence commune ces relents plébéiens, fut un soulagement immense que je dissimulai du mieux que je le pus sous l'apparence d'une obéissance contrainte. (BARBERY, 2006, p.16).22

Mas, ao mesmo tempo, a personagem Renée, antes de tal interdição, não sem indignação, fazia questão de "imprimir esse odor de subalternidade", de deixar ou dissimular o "traço" típico de sua classe social porque isso era o esperado pelos seus vizinhos economicamente privilegiados: "Il m'était si humiliant de devoir cuisiner ces mets infames." Por certo, o ato de a personagem Renée - que é uma concierge - cozinhar esses pratos metaforicamente "infames", mesmo em desacordo com as normas, é, ao mesmo tempo, dissimulação e opressão, pois sua liberdade individual de "obedecer dissimuladamente" está, na verdade, rendida a uma forma já interiorizada de poder e submissão; por outro lado, a personagem acaba por partilhar esse preconceito em relação aos referidos pratos, como pode ser visto na cena enunciativa acima citada.

Dessa forma, constrói-se aqui a imagem simbólica do oprimido diante do outro, por meio daquilo que DIGONNET (2008) chamará de "metáfora olfativa", ou seja, que pode utilizar a um alívio imenso que fiz o possível para disfarçar, sob a aparência de uma obediência forçada. (BARBERY, 2008, p.16)

20 O odor é uma impressão, uma ação de prensar sobre; uma ação pela qual uma coisa aplicada sobre a outra deixa nela uma marca. O odor aparece, então, como uma marca, qualquer coisa que deixa traço. (DIGONNET, apud JAMAIT, 2008, p.19 - tradução nossa)

21 O poder é uma presença ausente, uma virtualidade dotada de efeitos reais [...] que consiste em impor uma direção a uma pequena diversidade de indivíduos (RAMBEAU, 2006, p.56 - tradução nossa)

$22[\ldots]$ a intervenção do Senhor de Broglie [...] visando expulsar da vida em comum esses maus cheiros plebeus, foi um alívio imenso que fiz o possível para disfarçar, sob a aparência de uma obediência forçada. (BARBERY, 2008, p.16) 
percepção abstrata do odor para construir, esteticamente, determinados efeitos de sentido, de maneira a delimitar um tempo e um espaço, o qual marca e define determinadas ações e que perpetuam, ao fim e ao cabo, as relações opressivas e já interiorizadas de poder, como pode ser visto nessa outra cena da narrativa em questão, em que a concièrge continua a discorrer sobre sua alimentação:

C'était vingt-sept ans auparavant. Depuis, chaque jour, je vais chez le boucher acheter une tranche de jambon ou de foie de veau, que je coince dans mon cabas à filet entre le paquet de nouilles et la botte de carottes. J'exhibe complaisamment ces victuailles de pauvre, rehaussées de la caractéristique appréciable qu'elles ne sentent pas parce que je suis pauvre dans une maison de riches, afin d'alimenter conjointement le cliché consensuel et mon chat, Léon, qui n'est gras que de ces repas qui auraient dû m'être destinés et s'empiffre bruyamment de cochonnaille et de macaronis au beurre tandis que je peux assouvir sans perturbations olfactives et sans que personne n'en suspecte rien mes propres inclinations culinaires. (BARBERY, 2006, p.16). ${ }^{23}$

Como se vê, mesmo vinte e sete anos depois, a personagem continua o seu jogo de dissimulação: "J'exhibe complaisamment ces victuailles de pauvre, rehaussées de la caractéristique appréciable qu'elles ne sentent pas". Conforme o jogo metafórico proposto por Barbery, a metáfora imprimirá, agora, o "não odor" que torna esteticamente invisível o espaço do excluído social. De qualquer maneira, confirma-se aqui também a interdição proposta há vinte anos pelos referidos moradores, o que corrobora uma hierarquização muito demarcada que provoca a invisibilidade do indivíduo socioeconomicamente desfavorecido.

Dentro dessa mesma perspectiva, ou seja, do caráter dissimulador do jogo metafórico, como desencadeador do processo de construção das relações de poder entre as personagens, vejamos outro excerto de L'élégance du Hérisson, no citado diálogo da concierge com Pallières:

— Devriez lire l'Idéologie allemande, je lui dis, à ce crétin en duffle-coat vert sapin. Mais Antoine Pallières $[\ldots]$ me regarde, incertain de mes paroles étranges. — Direz bien le bonjour à votre maman, je marmonne en lui fermant la porte au nez et en espérant que la dysphonie des deux phrases sera recouverte par la force de préjugés millénaires. (BARBERY, 2006, p.13-14). ${ }^{24}$

Na cena enunciativa acima, a personagem, Antonio Pallières, é construída como "pseudo intelectual". Aqui, mais uma vez, a autora direciona o processo de "colonização simbólica" entre os personagens. Assim, na expressão, "la dysphonie des deux phrases sera recouverte par la force de préjugés millénaires. » fica bem marcado o lugar do "dominador" e daquele que 23 Isso foi há vinte e sete anos. Desde então, todo dia vou ao açougue comprar uma fatia de presunto ou de fígado de vitela, que enfio na minha sacola entre o pacote de macarrão e as cenouras. Exibo, condescendente, essas vitualhas de pobre, realçadas pela característica apreciável de que não têm cheiro, porque sou pobre num prédio de ricos, e assim alimento ao mesmo tempo o clichê consensual e meu gato, Leon, que só é gordo por causa dessas comidas que deveriam ser destinadas a mim, e que se empanturra ruidosamente de presunto e macarrão na manteiga, enquanto eu posso saciar minhas próprias simpatias culinárias, sem perturbações olfativas e sem que ninguém desconfie de nada. (BARBERY,2008, p.16)

24 - Tem que ler a Ideologia alemã", disse a esse cretino de parca verde-garrafa. [...] Mas Antoine Pallières olha para mim, duvidando de minhas estranhas palavras. [...] - Recomendações à senhora sua mãe, resmungo fechando a porta na cara dele e esperando que a disfonia das duas frases seja abafada pela força dos preconceitos milenares. (BARBERY, 2008, p.13-14) 
já está "dominado" dentro da hierarquia social e para quem também seria impossível devido à "force de préjugés milenaires" a leitura e a compreensão de um texto como a "ideologia alemã". Nessa mesma perspectiva, vejamos outra cena enunciativa:

Je chausse donc mes lunettes et déchiffre le titre. Léon Tolstoï, Anna Karénine. Avec une carte :

Chère Madame, En hommage à votre chat, Bien cordialement, Kakuro Ozu Il est toujours réconfortant d'être détrompée sur sa propre paranoïa. J'avais vu juste. Je suis démasquée. La panique fond sur moi. (BARBERY,2006, p.183 - grifo nosso). ${ }^{25}$

Nesse outro momento da narrativa, conforme mostra a cena acima, a chegada de um novo morador, M.Ozu, modifica o quadro enunciativo da trama. Tal personagem, ao contrário de Antonio Pallière, é realmente conhecedor da literatura e das artes e, por isso, reconhece na concierge, Renée, alguém com uma capacidade intelectual significativa. Nesse sentido, a expressão metafórica, "Je suis démasquées", denota o momento em que a personagem "M. Ozu" percebe que a concierge, Renée, possui um grande conhecimento sobre a literatura e as artes.

Entretanto, observa-se que tal "reconhecimento", que coloca a personagem Renée em lugar mais privilegiado, numa espécie de "descolonização simbólica", é feito do ponto de vista do "dominador", de mais um dos ricos moradores do prédio, ou seja, o M. Ozu - ainda que este personagem, enquanto estrangeiro, seja de uma cultura oriental e, portanto, com valores diferentes. Permanece, pois, no jogo metafórico a reverberação da hierarquização e, evidentemente, das relações de força e de poder.

Dentro dessa perspectiva, no primeiro excerto, o jogo metafórico aponta para a impossibilidade do saber ou da erudição dentro da realidade histórico-social daquele que é desfavorecido economicamente. Sendo a obra de Barbery situada na contemporaneidade, vale ressaltar, nesse caso, o que foi desenvolvido por Foucault, sobre a relação entre saber e domínio, principalmente a partir do século XVII, quando se criaram verdadeiros sistemas de controle sobre o "corpo", que passaram a determinar a vida dos indivíduos:

Au cours des XVIIème et XIIIème siècles, les mécanismes de pouvoir se seraient transformés, débordant le cadre juridique traditionnel du pouvoir pour pénétrer jusqu'au corps des individus, jusqu'à leur vie même. C'est ce que Foucault nomme le bio-pouvoir [...] pouvoir de gérer leur vie : non plus un pouvoir coercitif, mais un pouvoir qui produit, accroît et organise des forces. (RAMBEAU,2006, p.59). ${ }^{26}$

25 Portanto, ponho os óculos e decifro o título. Leon Tolstoi, Ana Karenina. com um cartão:

Prezada senhora, em homenagem ao seu gato, cordialmente, Kakuro Ozu.

É sempre reconfortante perder as ilusões a respeito da própria paranoia. Eu tinha visto certo. Fui desmascarada. O pânico cai em cima de mim. (BARBERY, 2008, p.183 - grifo nosso)

26 Ao longo dos séculos XVII e XVIII, os mecanismos de poder seriam transformados, ultrapassando o quadro jurídico tradicional do poder para penetrar até o corpo dos indivíduos, até as suas próprias vidas. Isto é o que Foucault denomina biopoder [...] poder de gerir sua vida: não mais um poder coercitivo, mas um poder que produz, aumenta e organiza forças. (RAMBEAU, 2006, p.59 - tradução nossa) 
Como se vê, conforme afirma Rambeau (2006) a respeito dos estudos de Foucault (1976) sobre o que ele denomina de "biopoder", existe na modernidade uma organização de forças que, implicitamente, conduzem e controlam o sujeito e influenciam suas relações consigo mesmo e com o outro. Por conseguinte, as expressões metafóricas " la dysphonie des deux phrases sera recouverte " e " Je suis démasquée " ressaltam, não somente a mudança de percepção dos interlocutores a respeito do enunciador, mas do próprio enunciador sobre si mesmo, o qual mascara-se nas mais diferentes "personas" (LIMA, 1991) para relacionar-se com o outro. Barbery.

Ainda nessa perspectiva, vejamos mais uma cena enunciativa do romance de Muriel

Le rituel du thé, cette reconduction précise des mêmes gestes et de la même dégustation, cette accession à des sensations simples, authentiques et raffinées, cette licence donnée à chacun, à peu de frais, de devenir un aristocrate du goût parce que le thé est la boisson des riches comme elle est celle des pauvres, le rituel du thé, donc, a cette vertu extraordinaire d'introduire dans l'absurdité de nos vies une brèche d'harmonie sereine. Oui, l'univers conspire à la vacuité, les âmes perdues pleurent la beauté, l'insignifiance nous encercle. Alors, buvons une tasse de thé. Le silence se fait, on entend le vent qui souffle au-dehors, les feuilles d'automne bruissent et s'envolent, le chat dort dans une chaude lumière. Et, dans chaque gorgée, se sublime le temps. (BARBERY, 2006, p.94). ${ }^{27}$

Na cena enunciativa descrita acima, a personagem Renée realiza "o rituel du thé" com sua melhor amiga, Manuela, a qual trabalha como faxineira no edifício da referida personagem concierge. É, pois, interessante observar, para além do tom poético do excerto, as metáforas que denotam a projeção imaginária das referidas personagens, para uma nova realidade econômicosocial a partir do referido "rituel du thé": "Le rituel du thé $[\ldots]$ cette accession à des sensations simples, authentiques et raffinées"; "[...] le thé est la boisson des riches comme elle est celle des pauvres" [...] (BARBERY, 2006, p.94)

Como se vê, o "gosto aristocrático" pelo chá transita entre os dois mundos, tanto o dos ricos quanto o dos pobres. O ritual de degustar o chá aproximaria os últimos dos primeiros, porém a recíproca não é verdadeira. Nesse sentido, apreciar o gosto e o aroma do chá, uma "boisson de riches", é uma metáfora para o tal "refinamento social" de que fala a narradora. Este refinamento é expresso de uma maneira peculiar, por meio de uma voz coletiva, "nós", para denotar o ritual do chá como um instante de refrigério e ascensão de todos os pertencentes à classe trabalhadora, ali representados por Renée e Manuela: « [...] a cette vertu extraordinaire d'introduire dans l'absurdité de nos vies une brèche d'harmonie sereine. Oui, l'univers conspire à la vacuité, les âmes perdues pleurent la beauté, l'insignifiance nous encercle. " (BARBERY,2006, p.94)

Nesse sentido, na metáfora da sublimação da dor dos excluídos por meio da degustação 27 O ritual do chá, essa recondução exata dos mesmos gestos e da mesma degustação, esse acesso a sensações simples, autênticas e requintadas, essa licença dada a cada um, a baixo custo, de se tornar um aristocrata do gosto, porque o chá é a bebida tanto dos ricos como dos pobres, o ritual do chá, portanto, tem essa virtude extraordinária de introduzir no absurdo de nossas vidas uma brecha de harmonia serena. Sim, o universo conspira para a vacuidade, as almas perdidas choram a beleza, a insignificância nos cerca. Então, bebamos uma xícara de chá. Faz-se o silêncio, ouve-se o vento que sopra lá fora, as folhas de outono sussurram e voam, o gato dorme sob uma luz quente. E, em cada gole, se sublima o tempo (BARBERY, 2008, p.95-96). 
do chá, são aguçados ao extremo, os sentidos dos indivíduos ali encenados, ou seja, o olfato, a audição, o paladar. Assim, a sensibilidade corporal permite transpor os limites da inquietação diária por meio de "une brèche d'harmonie sereine", uma vez que que cada gole de chá faz mergulhar as personagens num silêncio tão profundo da tranquilidade da alma, que os ruídos do vento, das folhas e do gato se fazem sentir de forma poética na sublimação ocorrida desse ritual. "Alors, buvons une tasse de thé. Le silence se fait, on entend le vent qui souffle audehors, les feuilles d'automne bruissent et s'envolent, le chat dort dans une chaude lumière. Et, dans chaque gorgée, se sublime le temps » (BARBERY,2006, p.94).

Assim, nessa construção metafórica elaborada por Barbery, sobre o ritual gustativo e olfativo do chá, as personagens transgridem, imaginariamente, os limites de sua classe social financeiramente menos favorecida, "como se" (Cf. ISER, In: LIMA, 2002, p.973) pudessem ascender-se e igualar-se socialmente aos ricos moradores do prédio em que moravam porque partilham com eles o mesmo hábito da degustação do chá. Entretanto, conforme a dicotomia instaurada entre os hábitos de ricos e pobres, na cena em questão, as diferenças sociais permanecem ali sugeridas, ao mesmo tempo em que se percebe o ressentimento de Renée e seu preconceito com a pobreza.

De fato, dentro da "realidade" da narrativa, Renée e Manuela são subjugadas pelo sistema onde estão inseridas, no que diz respeito não somente à repressão social, mas ao olhar do outro sobre essas personagens. Entretanto, o "ritual do chá" é a metáfora catalizadora da mudança para um espaço e tempo construídos "como se" (Cf. ISER, apud LIMA, 2002) todo processo de colonização e hierarquização simbólica se desvanecesse, o que desemboca na imagem da personificação e da poetização da realidade das personagens: “ [...] les feuilles d'automne bruissent et s'envolent, le chat dort dans une chaude lumière. Et, dans chaque gorgée, se sublime le temps" (BARBERY,2006, p.94), tornando, assim, possível a atenuação do processo de sujeição social somente no lugar do imaginário pela ação do aroma do chá como em Proust. ${ }^{28}$

Com efeito, no desenvolvimento do jogo metafórico para a construção de uma crítica social, política e cultural, não somente nas cenas aqui citadas, mas em toda a narrativa de L'élégance du Hérisson (2006), as vozes que se enunciam são marcadas por uma tomada de posição a respeito das relações de poder que regem os sujeitos imersos no contexto sociopolítico complexo da modernidade.

Por conseguinte, na fatura do texto, Barbery, põe em relevo a arte e a literatura como formas legítimas de reflexão, para uma tentativa de mudança em relação a si mesmo e ao outro, como exemplifica a fala da personagem Renée à respeito da necessidade da arte no "teatro patético" da vida humana: "vous avez désespérément besoin d'Art"; "[...] donner à ce théâtre pathétique la marque de l'Art et de ses ouvres majeures” (BARBERY, 2006, p.101-

28 Il y avait déjà bien des années que, de Combray, tout ce qui n'était pas le théâtre et le drame de mon coucher n'existait plus pour moi, quand un jour d'hiver, comme je rentrais à la maison, ma mère, voyant que j'avais froid, me proposa de me faire prendre, contre mon habitude, un peu de thé. Je refusai d'abord et, je ne sais pourquoi, me ravisai. Elle envoya chercher un de ces gâteaux courts et dodus appelés Petites Madeleines qui semblent avoir été moulés dans la valve rainurée d'une coquille de Saint-Jacques. Et bientôt, machinalement, accablé par la morne journée et la perspective d'un triste lendemain, je portai à mes lèvres une cuillerée du thé où j'avais laissé s'amollir un morceau de madeleine. Mais à l'instant même où la gorgée mêlée des miettes du gâteau toucha mon palais, je tressaillis, attentif à ce qui se passait d'extraordinaire en moi (PROUST, 1913, p.88-89). 
102). Afinal, uma sociedade marcada por hierarquizações está a serviço de mecanismos de poder (Cf. FOUCAULT, 1976), que regem os indivíduos das mais diferentes esferas sociais, distanciando-os da sensiblidade humana que pode ser aguçada por meio da arte, como foi possível exemplificar na arquitetura do texto de Muriel Barbery em L'élégance du Hérisson (2006).

Enuncia-se dessa forma, a maior metáfora do texto, porque é também a grande metáfora da experiência humana: a arte, a capacidade de criação que constitui o sujeito. Para Nancy Huston em seu livro L'espèce fabulatrice,

Les gens qui se croient dans le réel sont les plus ignorants, et cette ignorance est potentiellement meurtrière. Pour nous autres humains, la fiction est aussi réelle que le sol sur lequel nous marchons. Elle est ce sol. Notre soutien dans le monde. [...] Elaborées au long des siècles, ces fictions deviennent, par la foi que nous mettons, notre réalité la plus précieuse et la plus irrécusable. Bien que toutes tissés d'imaginaire, elles engendrent un deuxième niveau de réalité, la réalité humaine [...] Nous sommes l'espèce fabulatrice. (HUSTON, 2008, p.2930)

Portanto, a construção artístico-metafórica das personagens e da trama de Muriel Barbéry projeta o leitor para o universo transformador da arte, experenciada na realidade construída no livro, desde a metáfora presente no próprio título da obra, a qual é, a certa altura, desvelada pela personagem Paloma. Para esta última a personagem Renée possuía "a elegância do ouriço", ou seja, por fora poderia parecer espinhosa ou arredia, mas em seu interior carregava sensibilidade e elegância. ${ }^{29}$ Tais adjetivos, fazem referência ao poder transcendente da arte e da literatura, presentes na vida da concierge Renée - não obstante aos estereótipos sociais - o que denota também, entre outras coisas, conforme discutido neste artigo, uma visão crítica das mais diferentes formas de "colonização simbólica" entre os indivíduos encenados em L'élégance du Hérisson (2006).

\section{Referências}

AGAMBEN, Giorgio. Le pouvoir souverain et la vie nue. In: Hommo Sacer: L'intégrale (19972015). Tradução Marilène Raiola. Paris: Éditions du Seuil, 2016.

BARBÉRY, Muriel. A Elegância do ouriço. Tradução Rosa Freire Aguiar. São Paulo: Companhia das Letras, 2008.

BARBERY, Muriel. L'élégance du hérisson. Paris: Éditions Gallimard, 2006.

DIGONNET, Rémi. In : JAMET, Denis (org.). Les métaphores olfactives : du sensible à l'intelligible. In : Métaphore et perception : approches linguistiques, littéraire et philosophiques. Ed. L'Harmattan, Paris : 2008.

29 [...] Mme Michel, elle a l'élégance du hérisson : à l'extérieur, elle est bardée de piquants, une vraie forteresse, mais j'ai l'intuition qu'à l'intérieur, elle est aussi simplement raffinée que les hérissons, qui sont des petites bêtes faussement indolentes, farouchement solitaires et terriblement élégantes. (BARBERY, 2006, p.153) 


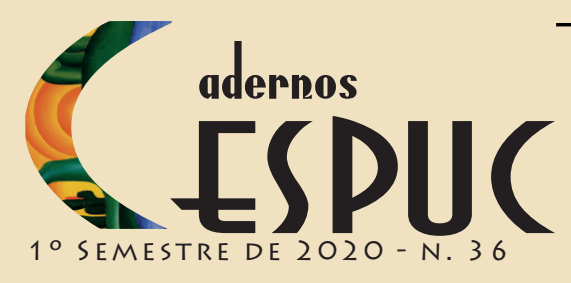

\section{Jozelma de Ouveira Ramos}

FOUCAULT, Michel. La volonté de savoir: droit de mort et pouvoir sur la vie. Paris: Éditions Gallimard, 1976.

HUSTON, Nancy. L’espèce fabulatrice. Paris: Babel, 2008.

ISER, Wolfgang. Os atos de fingir ou o que é fictício no texto ficcional. In: COSTA LIMA, Luiz (org.). Teoria da literatura em suas fontes, v. 2. Rio de Janeiro: Civilização Brasileira, 2002, p. 955-987.

JAMET, Denis. L'énonciation métaphorique en anglais et en français. Édition Lambert-Lucas. Limoges: 2009.

KONRAD, Hedwig. Étude sur la métaphore. In : . In : JAMET, Denis (org.). Sur la métaphore comme déplacement. In : Métaphore et perception : approches linguistiques, littéraire et philosophiques. Ed. L'Harmattan, Paris : 2008.

LIMA, Luiz Costa. Persona e sujeito ficcional. In: LIMA, Luiz Costa. Pensando nos Trópicos (Dispersa demanda II). Rio de Janeiro: Rocco, 1991.

RAMBEAU, Frédéric. Le texte en perspective: Dossier. In: FOUCAULT, Michel. La volonté de savoir: Droit de mort et pouvoir sur la vie. Paris: Folio plus philosophie, 2006.

STAËL, Mme. de: 1813, 110 - 3, cap. I da segunda parte. In: LIMA, Luiz Costa. Teoria da Literatura em suas fontes. vol.2. Rio de Janeiro: Civilização Brasileira, 2002. 